\title{
Thigmotropism and stretch-activated channels in the pathogenic fungus Candida albicans
}

\author{
H. J. Watts, ${ }^{1}$ A.-A. Véry, ${ }^{2} \dagger$ T. H. S. Perera, ${ }^{1}$ J. M. Davies ${ }^{2} \dagger$ \\ and N. A. R. Gow ${ }^{1}$
}

\begin{abstract}
Author for correspondence: N. A. R. Gow. Tel: +44 1224 273179. Fax: +44 1224273144.
\end{abstract} e-mail:n.gow@abdn.ac.uk

\footnotetext{
1 Department of Molecular \& Cell Biology, University of Aberdeen, Institute of Medical Sciences, Foresterhill, Aberdeen AB25 2ZN, UK

2 Plant Laboratory, University of York, PO Box 373, York Y01 5YW, UK
}

\begin{abstract}
The direction of growth of hyphae of the pathogenic fungus Candida albicans responds thigmotropically to surface contours by following scratches, ridges and grooves and by penetrating pores. Here it is shown that the thigmotropic response to ridges is attenuated by $\mathrm{GdCl}_{3}$ and verapamil [blockers of stretchactivated (SA) ion channels and L-type calcium channels, respectively]. At low concentrations, both compounds reduced the percentage of hyphae reorienting on contact with a ridge without markedly affecting hyphal extension rate, suggesting a possible role for SA or other calcium channels in the transduction of the thigmotropic response. In addition, patch-clamp recordings demonstrated SA channel activity in the plasma membrane of both yeast and hyphal cells of C. albicans. Two distinct SA channels with conductances of 54 pS and 20-25 pS in $200 \mathrm{mM} \mathrm{KCl}$ were observed in protoplasts from yeast cells and one channel of 51 pS was found in protoplasts from hyphal cells.
\end{abstract}

Keywords: Candida albicans, thigmotropism, stretch-activated channels

\section{INTRODUCTION}

Candida albicans is an opportunistic pathogen of humans, occurring as a normal commensal of up to $50 \%$ of asymptomatic individuals (Odds, 1988). It is a common agent of superficial mycoses of mucosal epithelia and an increasingly serious life-threatening pathogen in immunocompromised patients, being the fourth most common agent of septicaemia (Beck-Sagué \& Jarvis, 1993). The budding yeast form of this dimorphic fungus adheres strongly to mucosal surfaces, forming cavitations in epithelial surfaces (Ray \& Payne, 1988). Yeast cells can also give rise to tip-growing hyphae. The direction of hyphal growth is guided by grooves, ridges and pores in the substratum and it has been suggested that this contact guidance (thigmotropism) may facilitate hyphal invasion of host epithelia through membrane invaginations, wounds or points of weakened surface integrity (Sherwood et al., 1992; Gow et al., 1994; Gow, 1996).

Thigmotropism is a well-known property of cells that grow on surfaces and within solid substrates. Some

+Present address: Department of Plant Sciences, University of Cambridge, Downing Street, Cambridge CB2 3EA, UK.

Abbreviations: 10 , inside-out; SA, stretch-activated. plant-pathogenic fungi, including the rust fungi Uromyces appendiculatus and Puccinia hordei (Hoch et al., 1987; Read et al., 1992) and the rice blast fungus Magnaporthe grisea (Xiao et al., 1994), display thigmotropism during germ tube growth on plant surfaces. This behaviour seems to expedite location of stomata through which the fungi invade the plant surface. In addition, topographical features of stomatal guard cells serve as signals for induction of appressorium formation. Fabricated topographies on inert substrata, thought to mimic inductive topographies associated with guard cells, induced in vitro thigmodifferentiation of rust fungi germ tube apices into appressoria (Hoch $e t$ al., 1987; Read et al., 1997). The plasma membrane from germ tubes of $U$. appendiculatus also contains stretch-activated (SA) ion channels, which are permeable to $\mathrm{K}^{+}$and $\mathrm{Ca}^{2+}$ ions and inhibited by the SA channel blocker $\mathrm{Gd}^{3+}$ (Zhou et al., 1991). This suggests that localized stretching of the membrane by contact with a ridge may provide a sensing mechanism of substrate topological changes, possibly through local regulation of SA channels in regions of the apical membrane that are adpressed to a ridge or other topological discontinuity. Ion-channel-mediated changes in membrane voltage or cytoplasmic ion concentration, especially $\mathrm{Ca}^{2+}$, may then initiate signal transduction cascades leading to appressorium development or redirection of the axis of 
hyphal growth (Zhou et al., 1991; Gow, 1995). SA putatively calcium-permeable channels have also been implicated in the regulation of hyphal tip growth of Saprolegnia ferax and Neurospora crassa via the control of calcium influx (Garrill et al., 1993; Gow, 1995; Levina et al., 1995). SA ion channels regulated by membrane tension have also been described in a wide variety of animal, plant and bacterial cells and in other fungi (Sackin, 1995; Ding \& Pickard, 1993; Martinac et al., 1987; Gustin et al., 1988; Zhou \& Kung, 1992). The proposed roles for these channels include transduction of responses to changes in osmotic pressure, regulation of cell volume and growth and the sensation of touch or sound (Sackin, 1995).

Here, the effects of verapamil (a blocker of L-type $\mathrm{Ca}^{2+}$ channels) and gadolinium have been tested on the thigmotropic response of $C$. albicans hyphae, to investigate the possible roles of ion channels in the transduction of its thigmotropic behaviour. In addition, patch-clamp electrophysiology has been applied to $C$. albicans for the first time to demonstrate the presence of SA channels in the plasma membrane of both the hyphal and yeast forms of the fungus and to assess whether morphology-specific SA channels exist.

\section{METHODS}

Culture maintenance. Candida albicans strain 3153 was obtained originally from the London Mycological Reference Laboratory, Colindale, now transferred to the Mycological Reference Laboratory, Department of Microbiology, University of Leeds, UK. This is a germ-tube-positive strain that is fully virulent in systemic infections in mice. The strain was maintained on YPD $(1 \%, w / v$, yeast extract; $2 \%, w / v$, peptone; $2 \%, w / v$, glucose; Sigma) solidified with $2 \%(\mathrm{w} / \mathrm{v})$ agar, incubated at $30^{\circ} \mathrm{C}$.

Hyphal thigmotropism and extension rates. Topographically defined surfaces were used as described by Gow et al. (1994). The polystyrene membranes were a kind gift from Harvey Hoch, Cornell University, and had a ridge height of $1.53 \mu \mathrm{m}$ and pitch (distance from centre of ridge to centre of next ridge) of $20.0 \mu \mathrm{m}$. Polystyrene replica membranes were pressed, contoured surface down, onto serum agar plates containing $20 \%(\mathrm{w} / \mathrm{v})$ newborn calf serum (Gibco), solidified with $2 \%$ (w/v) agar. The membrane was then lifted off, inverted and placed contour side up on top of a fresh serum agar plate. These membranes are impermeable to nutrients but this procedure provided sufficient media on top of the membrane to support fungal growth. The small amount of medium that was lifted from the agar surface did not appear to influence the response to the topographical contours. In hyphal extension rate experiments, C. albicans was grown on serum agar plates without ridged membranes. For inhibition studies, channel blockers were filter-sterilized prior to incorporation into serum agar (stock inhibitor concentration of $1 \mathrm{mM}$ ).

An inoculum of C. albicans yeast cells was grown for $16 \mathrm{~h}$ at $25^{\circ} \mathrm{C}$ in $125 \mathrm{ml}$ liquid YPD medium to obtain stationary phase cells. For both thigmotropism and growth rate experiments, these cells were inoculated onto serum agar plates at approximately $2 \times 10^{4}$ cells $\mathrm{ml}^{-1}$ per plate, and incubated at $37^{\circ} \mathrm{C}$ to promote hypha formation.

Hyphal growth was recorded by time-lapse video microscopy (total magnification $\times 400$ ) in a constant temperature room at $37^{\circ} \mathrm{C}$. An Olympus CK2 inverted microscope was used to calculate hyphal extension rates and angles of hyphal approach to ridges by linking to a $\mathrm{BBC}$ master computer with image analysis software (Gray \& Morris, 1992). Experiments were recorded on a Panasonic AG-6720 time-lapse video cassette recorder. The angle of approach of the hypha at the point at which it encountered a ridge was determined as in Fig. 1. The numbers of hyphae which reoriented and subsequently grew along the groove or ridge upon encountering the ridge were expressed as a percentage of the total, subjected to arcsin transformation (John \& Quenouille, 1977) and plotted against the angle of approach. Hyphal extension rates were calculated over a $6 \mathrm{~h}$ growth period.

Preparation of protoplasts. The method for protoplast preparation and channel recording was adapted from that described for Saccharomyces cerevisiae (Bertl \& Slayman, 1992). To prepare protoplasts from yeast cells, C. albicans was grown overnight at $25^{\circ} \mathrm{C}$ (shaking at 200 r.p.m.) in Difco Yeast Nitrogen Base (YNB; with amino acids) supplemented with $5 \mathrm{~g}$ glucose $1^{-1}$. A $0.5 \mathrm{ml}$ sample of cells was centrifuged $\left(1500 \mathrm{~g}, 4^{\circ} \mathrm{C}, 5 \mathrm{~min}\right)$, resuspended in $0.5 \mathrm{ml}$ of a solution containing $50 \mathrm{mM} \mathrm{KH_{2 }} \mathrm{PO}_{4}, 5 \mathrm{mM}$ EDTA, $50 \mathrm{mM}$ DTT adjusted to $\mathrm{pH} 7 \cdot 2$ with $\mathrm{KOH}$ and incubated with gentle agitation at $30^{\circ} \mathrm{C}$ for $30 \mathrm{~min}$. An equal volume of a solution containing $50 \mathrm{mM} \mathrm{KH_{2 }} \mathrm{PO}_{4}, 40 \mathrm{mM}$ 2-mercaptoethanol, $2 \cdot 4 \mathrm{M}$ sorbitol, $3 \mu \mathrm{g}$ chitinase $\mathrm{ml}^{-1}$ (10 units $\mathrm{g}^{-1}$; Sigma), $1.8 \mu \mathrm{g}$ lyticase $\mathrm{ml}^{-1}\left(200-1000\right.$ units $\mathrm{mg}^{-1}$; Sigma) and $12 \mu \mathrm{l} \beta$ glucuronidase $\mathrm{ml}^{-1}$ (100000 units $\mathrm{ml}^{-1}$; Sigma), $\mathrm{pH} 7 \cdot 2$ with $\mathrm{KOH}$, was added. The cells were incubated for a further $45 \mathrm{~min}$ at $30^{\circ} \mathrm{C}$ with gentle agitation. Protoplasts were harvested by centrifugation $\left(1500 \mathrm{~g}, 4^{\circ} \mathrm{C}, 5 \mathrm{~min}\right)$ and resuspended in $0.5 \mathrm{ml}$ of a solution containing (in mM) $200 \mathrm{KCl}$, $10 \mathrm{CaCl}_{2}, 10 \mathrm{MgCl}_{2}, 10$ glucose, $345 \mathrm{D}$-sorbitol and 5 HEPES/Tris, $\mathrm{pH} 7 \cdot 2$.

To prepare protoplasts from hyphal cells, an inoculum of yeast cells was first grown overnight as described before. The cells were washed in distilled water, diluted $1 / 10$ into YNB (final volume $25 \mathrm{ml}$; adjusted to $\mathrm{pH} 8.0$ with $20 \mathrm{mM}$ Tris/MES) and incubated in a shaking water bath (200 r.p.m.) at $37^{\circ} \mathrm{C}$ for $4 \mathrm{~h}$. Hyphae were harvested and protoplasts were prepared as before. The final protoplast suspension was filtered through a nylon mesh filter ( $20 \mu \mathrm{m}$ porosity) to remove non-digested cells and resuspended as for yeast protoplasts.

Patch-clamp recordings. Standard patch-clamp techniques as described by Hamill et al. (1981) were used. Pipettes were fabricated from thin-walled borosilicate glass capillaries (Kimble) and coated with Sylgard (Dow Corning). The pipettes had a resistance of $15-20 \mathrm{M} \Omega$ when filled with pipette solution. This consisted of $50 \mathrm{mM} \mathrm{KCl}$ and $1 \mathrm{mM} \mathrm{MgCl}$, buffered to $\mathrm{pH} 5.6$ with $5 \mathrm{mM}$ MES/Tris for yeast protoplasts or to $\mathrm{pH} 7 \cdot 2$ with $5 \mathrm{mM}$ HEPES/Tris for hyphal protoplasts. The reference $\mathrm{Ag} / \mathrm{AgCl}$ half cell was filled with the relevant pipette solution and solidified with $1 \%(\mathrm{w} / \mathrm{v}$ ) agar. The bath solution consisted of $200 \mathrm{mM} \mathrm{KCl}, 10 \mathrm{mM} \mathrm{CaCl}$ and $10 \mathrm{mM}$ $\mathrm{MgCl}_{2}$, buffered to $\mathrm{pH} 7 \cdot 2$ with $5 \mathrm{mM}$ HEPES/Tris. The osmolarity of both pipette and bath solutions was adjusted to 925 mOsM with D-sorbitol ( $>98 \%$ purity; Sigma). The patch-clamp amplifier was an L/M PC (List Electronics). Voltage pulse protocols, data acquisition and analysis were performed using CED software (Cambridge Electronic Design). Data were low passed filtered at $1 \mathrm{kHz}$ and sampled at $3 \mathrm{kHz}$. Pressure applied through the pipette was measured with a pressure monitor (World Precision Instruments). The mean number of open channels as a function of applied pressure was determined by dividing the integral of the total single channel current by the channel unitary current and the length of the voltage pulse. 




Fig. 1. Percentage reorientation of $C$. albicans hyphae upon contact with a ridge on a polystyrene membrane replica (height $1.53 \mu \mathrm{m}$, pitch $20 \mu \mathrm{m}$ ) against the angle of approach $(\sigma)$ to the ridge in the presence of $50 \mu \mathrm{M} \mathrm{GdCl}_{3}$ (plain bars) or $50 \mu \mathrm{M}$ verapamil (hatched bars) or in the absence of channel inhibitors (solid bars). Results are presented as the mean ( $t$ SD) of 300 determinations in three independent experiments. The inset shows the angle of approach $(\sigma)$ defined as that between the hypha and the ridge.

\section{RESULTS}

\section{Growth of C. albicans hyphae on ridged surfaces}

Previous work demonstrated that the hyphal cells of $C$. albicans responded to thigmotropic cues, following grooves, ridges and entering pores of membrane substrates (Sherwood et al., 1992; Gow et al., 1994). It was observed that the angle of approach of a hypha to a ridge was related to whether the hypha reoriented upon making contact with that ridge and this was used to quantitate the thigmotropic response. Hyphae were grown on polystyrene membranes with ridges of $1.53 \mu \mathrm{m}$ height and $20.0 \mu \mathrm{m}$ pitch; the percentage of hyphae which changed growth direction to follow the ridge was recorded as a function of the angle of approach (Fig. 1). Greater than $82-90 \%$ of the hyphae changed their direction of growth on contact with a ridge when approaching at angles of $0-30^{\circ}$. As the angle increased, the number of hyphae reorienting decreased up to approach angles of $71-90^{\circ}$ where virtually no reorientation in growth direction was observed (Fig. 1).

In the presence of either $50 \mu \mathrm{M}$ verapamil or $50 \mu \mathrm{M}$ $\mathrm{GdCl}_{3}$, the percentage of hyphae reorienting on contact with a ridge was reduced (Fig. 1). For example, at approach angles of $41-50^{\circ}$ only $4-8 \%$ of hyphae reoriented in the presence of verapamil or gadolinium compared to $67 \%$ of hyphae in control experiments. The percentage response in the presence of either verapamil or $\mathrm{Gd}^{3+}$ was significantly different to control values (by Student's $t$-test) at the $0.1 \%$ confidence limit in each of the $10^{\circ}$ intervals up to and including $70^{\circ}$. Control experiments showed that $50 \mu \mathrm{M} \mathrm{GdCl}_{3}$ or $50 \mu \mathrm{M}$ verapamil did not inhibit hyphal extension rates on solid serum-containing agar. In the absence of inhibitors, the hyphal extension rate was $25.2 \pm$ $5.8 \mu \mathrm{m} \mathrm{h}^{-1}$ compared to $28.5 \pm 11.1 \mu \mathrm{m} \mathrm{h}^{-1}$ and $27.6 \pm$ $5.4 \mu \mathrm{m} \mathrm{h}^{-1}$ (mean $\pm \mathrm{SD}, n=12-19$ ) in the presence of $50 \mu \mathrm{M}$ gadolinium and $50 \mu \mathrm{M}$ verapamil, respectively. Measurable attenuation of the reorientation effects of hyphae to ridges could also be measured in 10 and $20 \mu \mathrm{M}$ gadolinium and 10 and $20 \mu \mathrm{M}$ verapamil, although these were less marked than at the higher concentration (data not shown).
Other channel blockers, for example $50 \mu \mathrm{M} \mathrm{Co}^{2+}$ and $50 \mu \mathrm{M} \mathrm{La}^{2+}$, were also tested but found to reduce the hyphal extension rate significantly in addition to affecting the thigmotropic response.

\section{SA channels in the plasma membrane of $C$. albicans}

Enzymic digestion of the cell wall formed spherical protoplasts, typically of $5 \mu \mathrm{m}$ diameter. Seals of $10 \mathrm{G} \Omega$ were obtained in approximately $50 \%$ of attempts with yeast cell protoplasts but seal formation on hyphal cell protoplasts proved to be more difficult. The inside-out (IO) excised patch configuration was readily obtained by the addition of strong positive pressure lasting from a few seconds to several minutes. Whole-cell recording was also achieved but was found to be too fragile to withstand the application of pressure. Hence the outside-out excised patch configuration for testing the effects on single channel activity of channel blockers at the external membrane face was not attained. However, in the longer term it may be possible to develop a pipette perfusion system suitable for use with Candida which would allow drug delivery to this site.

Two types of SA channels were observed in IO patches from yeast protoplasts. An example of SA channel activity from a yeast cell protoplast is shown in Fig. 2. The activity of this channel increased appreciably when pressure was applied (Fig. 2a). The channel had a conductance of approximately $54 \mathrm{pS}$ (Fig. 2b) and was permeable to both cations and anions as indicated by its relative permeability ratio $\left\langle P_{\mathrm{Cl}} / P_{\mathrm{K}}=1.5\right.$; estimated from the extrapolated reversal voltage). It was activated by both positive and negative pressure but activity was greater at positive pressure (Fig. 2c).

A second SA channel type (Fig. 3a) was often observed in yeast cell protoplasts $(n=6)$. This channel had a smaller conductance $(20-25 \mathrm{pS})$ and was, in contrast to the other yeast channel, strongly outwardly rectifying (Fig. 3b). A weak cation selectivity was observed $\left(P_{\mathrm{K}} / P_{\mathrm{Cl}}=3.5\right)$.

SA channel activity was also observed in hyphal protoplasts (Fig. 4). The channel was, like those observed in yeast, only active when pressure was applied (Fig. 4a). It had a conductance of 51 pS (Fig. 4b), similar 
(a)
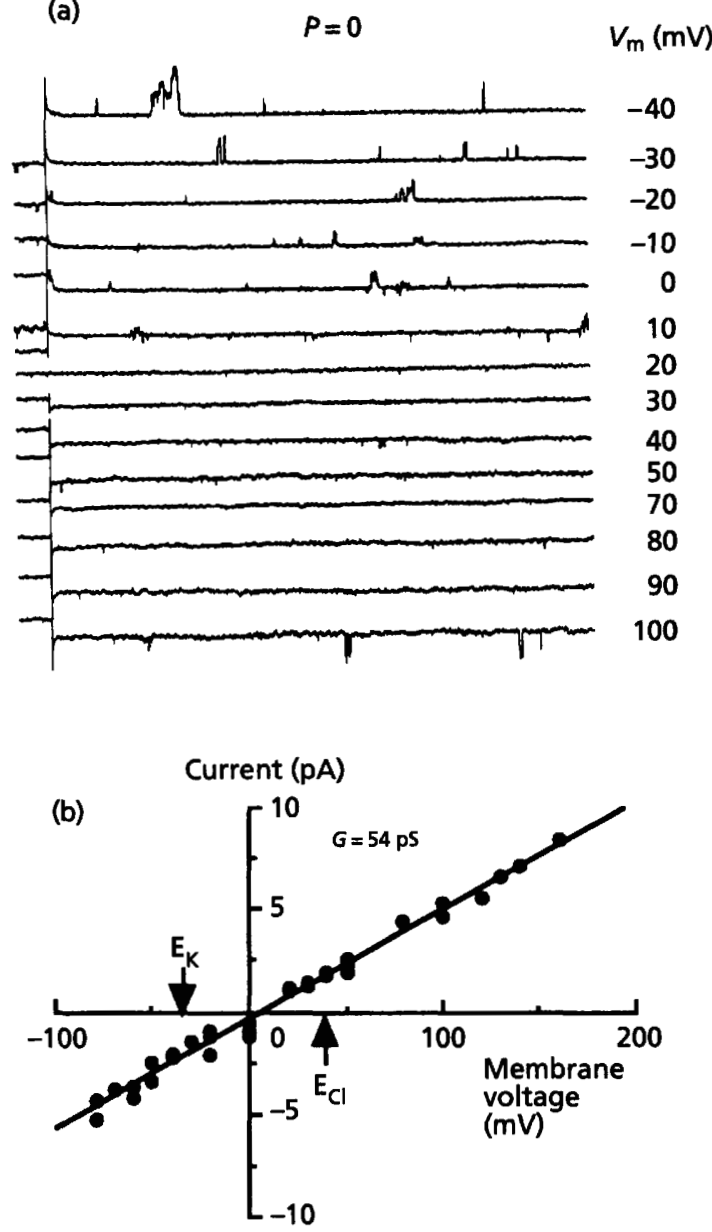
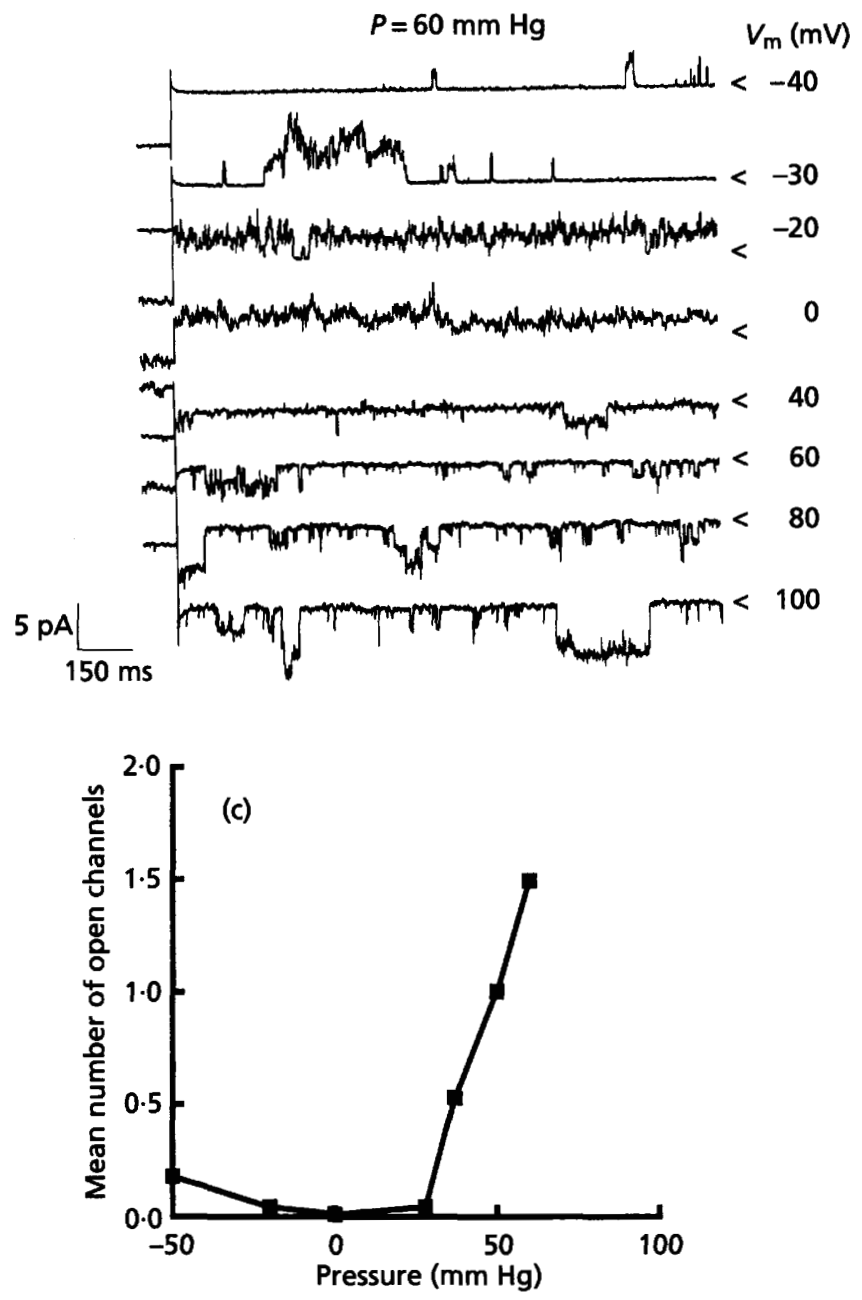

Fig. 2. SA channel activity from a $C$. albicans yeast cell protoplast. Pipette and bath solutions were as given in Methods. (a) Recordings from an 10 excised patch: left panel, single channel activity without applied pressure $(P=0)$; right panel, the same patch under $+60 \mathrm{~mm} \mathrm{Hg}$ pressure. The holding voltage was $+20 \mathrm{mV}$; applied voltages $\left(V_{\mathrm{m}}\right)$ are indicated on the right of each set of traces. The current level with the channel in a closed state is marked ' $<$ '. (b) Current-voltage relationship of the SA single channel activity represented in (a). Current flowing above the voltage axis represents positive charge flow from the cytosolic to the extracellular membrane face. The equilibrium voltage for $\mathrm{K}^{+}$is marked as ' $\mathrm{E}_{\mathrm{K}}$ '. Channel conductance $(G)$ was estimated as $54 \mathrm{pS}$ from the regression fitted to channel activity; relative permeability was estimated from the extrapolated voltage intersect. (c) Effect of pressure on activity of the 54 pS channel.

to the larger yeast channel observed, and was also only weakly selective $\left(P_{\mathrm{Cl}} / P_{\mathrm{K}}=2 \cdot 5\right)$. The hyphal channel was also sensitive to voltage, opening preferentially at positive membrane potentials. In contrast to the larger yeast channel, it was more sensitive to negative rather than positive membrane pressures (Fig. 4c).

\section{DISCUSSION}

Fungal hyphae, including those of C. albicans, have been shown to respond to thigmotropic cues. Previous work with the plant-pathogenic fungus $U$. appendiculatus suggested that SA channels may be involved in the sensing of substrate topography and induction of appressorium formation (Zhou et al., 1991). In this study, the numbers of C. albicans hyphae responding to a thigmotropic cue of ridges on polystyrene replica membranes were reduced in the presence of an SA channel inhibitor, gadolinium, and an L-type calcium channel blocker, verapamil. This suggests that SA and/or other calcium-permeable channels could be involved in the thigmotropic response, although there remains the possibility of non-specific effects of the inhibitors on whole cells. Verapamil can produce direct block of potassium selective channels (Thomine et al., 1994) and gadolinium can affect ostensibly non-SA channels (Allen \& Sanders, 1994). However, verapamil and gadolinium did not inhibit hyphal elongation, even at the highest concentration used, suggesting that their effects were specific to the thigmotropic response. 
(a)

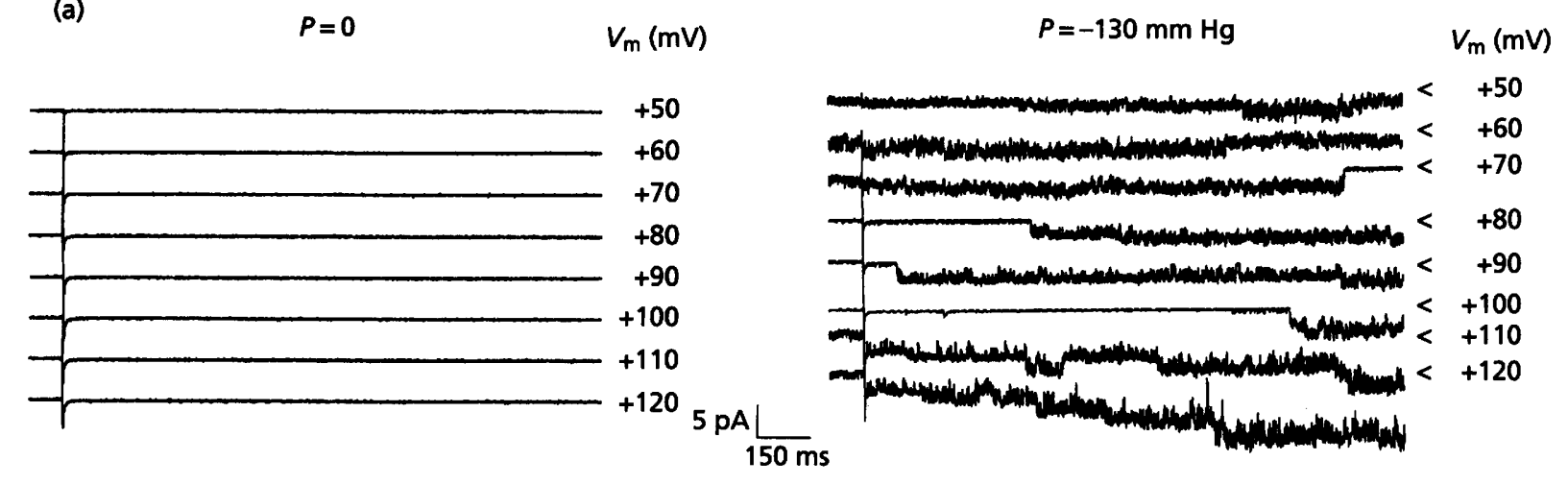

Fig. 3. Smaller conductance channel from $C$. albicans yeast cells. Recording conditions were identical to those of Fig. 2. (a) Single channel activity in an excised 10 patch under control conditions (left panel; $P=0$ ) and then under negative pressure (right panel; $P=-130 \mathrm{~mm} \mathrm{Hg}$ ). The holding voltage was $+40 \mathrm{mV} ;$ ' $<$ ' denotes channel closed state. (b) Current-voltage relationship of SA single channel activity from (a). Channel opening was not observed at applied negative voltages. Channel conductance was estimated to be $23 \mathrm{pS}$ in this example.

The presence of SA channels in the plasma membrane of C. albicans was demonstrated by patch-clamp electrophysiology. Although a preliminary characterization, it represents the first single channel recordings from a medically important fungus. Small protoplast size has not precluded the formation of high resistance seals from either yeast or hyphal forms of a clinical isolate and artificially enlarged strains, for example those produced by colchicine treatment (Jibiki et al., 1993), did not need to be used.

The smaller of the two SA channels observed in the yeast form $(20-25 \mathrm{pS})$ bears some resemblance to the YORK channel, a $26 \mathrm{pS}$ outward rectifier of the Sac. cerevisiae plasma membrane (Lesage et al., 1996). Although the latter appears to be stretch-insensitive when expressed in Xenopus laevis oocytes, the smaller C. albicans yeast channel could be a functional homologue. As such the physiological role of this low conductance channel in $C$. albicans yeasts cells may lie primarily in facilitating rapid cellular $\mathrm{K}^{+}$efflux for osmoregulation. If this channel were retained in the hyphal form, its $\mathrm{Ca}^{2+}$ permeability (which was not determined in this study) could be a determinant of its ability to play a role in thigmotropic sensing.

Two weakly cation-selective SA channels of similar conductance were observed in the yeast $(54 \mathrm{pS})$ and hyphal $(51 \mathrm{pS}$ ) forms; however, as differences were observed in their voltage dependence and response to pressure it cannot be concluded at this point that the $54 \mathrm{pS}$ yeast channel is equivalent to the $51 \mathrm{pS}$ hyphal channel. If this yeast channel proved to be yeast-specific, then it may play a role in turgor responses as it was activated by both positive and negative pressures. In Sac. cerevisiae, a non-selective mechanosensitive channel has been suggested to play such a role in osmoregulation (Gustin et al., 1988). However, it is also possible that the observed channel responses to pressure were related to the patch-clamp configuration used. For example, an SA channel characterized in Schizosaccharomyces pombe plasma membrane was activated by positive pressure in cell-attached mode but could be activated by either pressure or suction in excised patches (Zhou \& Kung, 1992).

The hyphal $51 \mathrm{pS}$ channel is perhaps the most obvious candidate for a thigmotropism signal transducer. However, the hyphal channel was activated by negative pressure, whereas membrane deformation of a hyphal tip on making contact with a ridge would be equivalent to application of positive pressure in the patch-clamp experiments. This channel may yet have a role in thigmotropism if it is considered that the hydrostatic pressure created in vivo within the hypha and directed towards the tip is functionally equivalent to the negative pressure applied to the IO patch. It is possible that in vivo the channel is maintained preferentially in an open state and it is its closure on contact of the tip with a solid surface that is relevant to thigmotropic sensing. As yet this remains a speculative explanation with no direct supporting evidence from other tip-growing cell types.

Our pharmacological analysis of the thigmotropic response of Candida hyphae suggests that the specific 

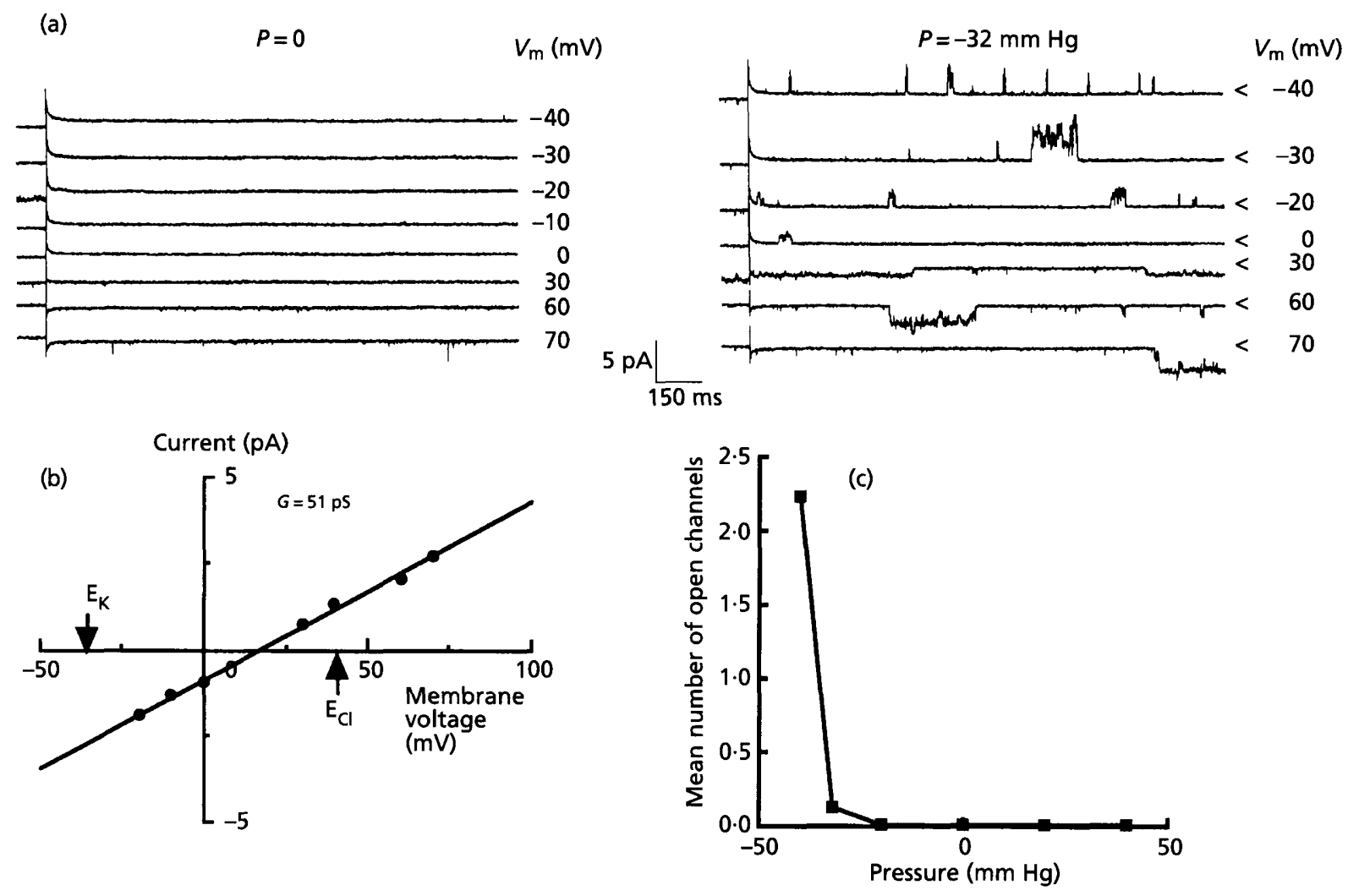

Fig. 4. SA channel activity in an IO patch from a $C$. albicans hyphal protoplast. Recording conditions were as given in Fig. 2 with the exception that the pipette solution was adjusted to $\mathrm{pH} 7.2$ with $5 \mathrm{mM} \mathrm{HEPES} / \mathrm{Tr}$ ris. (a) Single channel activity under control conditions (left panel; $P=0$ ) and then under negative pressure (right panel; $P=-32 \mathrm{~mm} \mathrm{Hg}$ ). The holding voltage was $+40 \mathrm{mV} ;$ ' $<$ ' denotes channel closed state. (b) Current-voltage relationship of SA channel activity from (a). Single channel conductance was estimated as $51 \mathrm{pS}$. (c) Effect of pressure applied on channel activity.

plasma membrane channels involved in this behaviour may not be essential for hyphal extension. In N. crassa, $500 \mu \mathrm{M} \mathrm{Gd}{ }^{3+}$ incompletely inhibited stretch channel activity and only inhibited hyphal extension transiently, indicating that such channels were not essential for tip growth (Levina et al., 1995). However, in the oomycete Sap. ferax $\mathrm{Gd}^{3+}$ dissipated the tip high cytosolic calcium gradient and stopped hyphal growth (Garrill et al., 1993). Although a functional role for SA channel activity in Candida hyphal thigmotropism has not been established unequivocally in this study, the ability to form stable IO patches from the plasma membrane will enable further investigation of this hitherto unexplored facet of Candida biology. Thorough characterization of Candida single channel activity will enable assessment of channel interaction with, for example, the signal transduction cascades and changes in cytoskeletal architecture which are thought to be relevant not only to contact sensing but also to osmotolerance, polarized hyphal growth and the dimorphic switch.

\section{ACKNOWLEDGEMENTS}

We thank the following for financial support: (to N.A.R.G.) University of Aberdeen Research Committee (with I. R. Booth), the BBSRC (ROPA grant no. 1/CEL 04556), The Royal Society/Leverhulme Senior fellowship scheme, the
Wellcome Trust and Glaxo Group Research; (to J.M.D.) BBSRC (grant no. PO4954) and The Royal Society of London. The use of patch-clamp equipment at the University of York (Professor D. Sanders) is gratefully acknowledged as well as useful advice from Natasha Levina.

\section{REFERENCES}

Allen, G. J. \& Sanders, D. (1994). Two voltage-gated, calcium release channels coreside in the vacuolar membrane of broad bean guard cells. Plant Cell 6, 685-694.

Beck-Sagué, C. M. \& Jarvis, W. R. (1993). Secular trends in the epidemiology of nosocomial fungus infections in the United States, 1880-1990. J Infect Dis 167, 1247-1252.

Bertl, A. \& Slayman, C. L. (1992). Complex modulation of cation channels in the tonoplast and plasma membrane of Saccharomyces cerevisiae: single channel studies. J Exp Biol 172, 271-287.

Ding, J. P. \& Pickard, B. G. (1993). Mechanosensory calciumselective cation channels in epidermal cells. Plant J 3, 83-110.

Garrill, A., Jackson, S. L., Lew, R. R. \& Heath, I. B. (1993). Ion channels and tip growth: stretch activated channels generate a $\mathrm{Ca}^{2+}$ gradient essential for hyphal growth. Eur J Cell Biol 60, 358-365.

Gow, N. A. R. (1995). Tip growth and polarity. In The Growing Fungus, pp. 277-299. Edited by N. A. R. Gow \& G. M. Gadd. London: Chapman \& Hall. 
Gow, N. A. R. (1996). Candida albicans: morphogenesis and pathogenesis. Jpn J Med Mycol 37, 49-58.

Gow, N. A. R., Perera, T. H. S., Sherwood-Higham, J., Gooday, G. W., Gregory, D. W. \& Marshall, D. (1994). Contact sensing in Candida albicans: a possible aid to epithelial penetration. $J$ Med Vet Mycol 30, 461-469.

Gray, D. I. \& Morris, B. M. (1992). A low cost video analysis system for the BBC Master computer. Binary Comput Microbiol 4, $58-61$.

Gustin, M. C., Zhou, X.-L., Martinac, B. \& Kung, C. (1988). A mechanosensitive ion channel in the yeast plasma membrane. Science 242, 762-765.

Hamill, O. P., Marty, A., Neher, E., Sakmann, B. \& Sigworth, F. J. (1981). Improved patch clamp technique for high resolution current recording from cells and cell-free membrane patches. Pflueg Arch Eur J Physiol 391, 85-100.

Hoch, H. C., Staples, R. C., Whitehead, B., Comeau, J. \& Wolf, E. D. (1987). Signalling for growth orientation and cell differentiation by surface topography in Uromyces. Science 235, 1659-1662.

Jibiki, M., Kuno, Y., Shinoyama, H. \& Fujii, T. (1993). Isolation and properties of large cell strains from a methanol-utilizing yeast, Candida sp. N-16 by colchicine treatment. J Gen Appl Microbiol 39, 439-442.

John, J. A. \& Quenouille, M. M. (1977). Experiments: Design and Analysis, 2nd edn. London: Charles Griffin.

Lesage, F., Guillemare, E., Fink, M., Duprat, F., Lazdunski, M., Romey, G. \& Barhanin, J. (1996). A pH-sensitive yeast outward rectifier $\mathrm{K}^{+}$channel with two pore domains and novel gating properties. J Biol Chem 271, 4183-4187.

Levina, N. N., Lew, R. R., Hyde, G. J. \& Heath, I. B. (1995). The roles of $\mathrm{Ca}^{2+}$ and plasma membrane ion channels in hyphal tip growth of Neurospora crassa. J Cell Sci 108, 3405-3417.

Martinac, B., Beuchner, M., Delcour, A. H., Adler, J. \& Kung, C. (1987). Mechanosensitive ion channel in Escherichia coli. Proc Natl Acad Sci USA 84, 2297-2301.
Odds, F. C. (1988). Candida and Candidosis, 2nd edn. New York: Baillière Tindall.

Ray, T. L. \& Payne, C. D. (1988). Scanning electron microscopy of epidermal adherence and cavitation in murine candidiasis: a role for Candida acid proteinase. Infect Immun 56, 1942-1949.

Read, N. D., Kellock, L. J., Knight, H. \& Trewavas, A. J. (1992). Contact sensing during infection by fungal pathogens. In Perspectives in Plant Cell Recognition, pp. 137-172. Edited by J. A. Callow \& J. R. Green. Cambridge: Cambridge University Press.

Read, N. D., Kellock, L. J., Collins, T. J. \& Gundlach, A. M. (1997). Role of topography sensing for infection-structure differentiation in cereal rust fungi. Planta 202, 163-170.

Sackin, H. (1995). Mechanosensitive channels. Annu Rev Physiol 57, 333-353.

Sherwood, J., Gow, N. A. R., Gooday, G. W., Gregory, D. W. \& Marshall, D. (1992). Contact sensing in Candida albicans: a possible aid to epithelial penetration. J Med Vet Mycol 30, 461-469.

Thomine, S., Zimmerman, S., Vandujin, B. \& Barbier-Brygoo, H. (1994). Calcium channel antagonists induce direct inhibition of the outward rectifying potassium channel in tobacco protoplasts. FEBS Lett 340, 45-50.

Xiao, J.-Z., Watanabe, T., Kamakura, T., Ohshima, A. \& Yamaguchi, I. (1994). Studies on cellular differentiation of Magnaporthe grisea. Physicochemical aspects of substratum surfaces in relation to appressorium formation. Physiol Mol Plant Pathol 44, 227-236.

Zhou, X.-L. \& Kung, C. (1992). A mechanosensitive ion channel in Schizosaccharomyces pombe. EMBO J 11, 2869-2875.

Zhou, X.-L., Stumpf, M. A., Hoch, H. C. \& Kung, C. (1991). A mechanosensitive channel in whole cells and in membrane patches of the fungus Uromyces. Science 253, 1415-1417.

Received 6 August 1997; revised 22 October 1997; accepted 31 October 1997. 